\title{
FORMAÇÃO DE PROFESSORES DA EDUCAÇÃO INFANTIL: REFLEXÕES SOBRE A NECESSÁRIA INSTRUMENTALIZAÇÃO TEÓRICA DO PROFISSIONAL ATUANTE COM CRIANÇA COM OU SEM DEFICIÊNCIA
}

\author{
FORMACIÓN DE PROFESORES DE EDUCACIÓN INICIAL: REFLEXIONES \\ SOBRE LA NECESIDAD DE ACCIÓN PROFESIONAL \\ INSTRUMENTALIZACIÓN TEÓRICO CON NIÑOS CON Y SIN DISCAPACIDAD
}

TEACHER TRAINING OF EARLY CHILDHOOD EDUCATION: REFLECTIONS ON THE NEED INSTRUMENTALIZATION PROFESSIONAL THEORETICAL ACTING WITH CHILDREN WITH OR WITHOUT DISABILITIES

\author{
Gabriely Cabestré AMORIM ${ }^{1}$ \\ Elieuza Aparecida de LIMA ${ }^{2}$ \\ Rita de Cássia Tibério ARAÚJO 3
}

RESUMO: Com a perspectiva de que os processos de formação de professores são constituições sociais e históricas, cuja temática é foco de pesquisas atuais efetivadas nas últimas décadas, este artigo propõe-se a identificar e discutir o perfil de professores que atuam na Educação Infantil em turmas de crianças com ou sem deficiência. Participaram do estudo vinte e seis professores (especialistas e regentes) atuantes em um município do interior paulista. Para a produção de dados, os participantes responderam uma entrevista, cujos resultados obtidos demonstram indícios para refletirmos sobre a formação inicial e continuada de professores, o tempo de experiência dos profissionais entrevistados e o impacto desses fatores no processo de formação docente para e na prática educativa em turmas de crianças pequenas. Os dados encontrados demonstraram que os profissionais entrevistados possuem formação em Pedagogia, sendo que a maioria dos professores especialistas possui pós-graduação em Educação Especial, de forma generalista e/ou por área de deficiência/transtorno, já os professores regentes possuem formação prevalentemente voltada à psicopedagogia. Além disso, os entrevistados revelaram que a carga horária de trabalho inviabiliza a formação continuada; outro ponto a ser destacado foi que os professores regentes relataram dificuldade em ensinar a criança com deficiência, por não terem formação adequada.

PALAVRAS-CHAVE: Formação de Professores. Educação Infantil. Educação Especial. Deficiência.

\footnotetext{
${ }^{1}$ Doutoranda em Educação, Universidade Estadual Paulista (UNESP) - Marília. Mestre em Educação na área de Educação Especial - UNESP/Marília (2015). Possui graduação em Pedagogia pela UNESP/Bauru (2010), Aperfeiçoamento em Produção de Material Didático para Diversidade pela UNESP/Bauru (2015). E-mail: gcabestre@gmail.com

${ }^{2}$ Docente do curso de Pedagogia e do Programa de Pós-Graduação em Educação da FFC, Universidade Estadual Paulista (UNESP) - Marília/SP. Possui Graduação em Pedagogia (1996), mestrado em Educação (2001) e Doutorado em Educação (2005) pela UNESP/Marília. Integra o quadro de assessores científicos da Fundação de Amparo à Pesquisa do Estado de São Paulo (Fapesp). E-mail: aelislima2013@ gmail.com ${ }^{3}$ Professora assistente doutora da Universidade Estadual Paulista (UNESP) - Marília. Possui graduação em Terapia Ocupacional pela Universidade de São Paulo (1975), mestrado em Educação (1993) e doutorado em Educação (1998) pela UNESP/Marília. E-mail: ritac@ marilia.unesp.br
} 
RESUMEN: Con la perspectiva de que los procesos de formación de profesores son constituciones sociales e históricas, cuyo tema es el efecto de foco de investigación actual en las últimas décadas, este artículo busca identificar y analizar el perfil de profesores que trabajan en la educación preescolar en clases de niños con o sin discapacidad. Participaron en este estudio veinte y seis profesores (especialistas y regentes) operan en una ciudad en el estado de São Paulo. Para la producción de datos, los participantes respondieron a una entrevista, los resultados obtenidos muestran signos para reflexionar sobre la formación inicial y continua de profesores, la experiencia de los profesionales entrevistados y el impacto de estos factores sobre el proceso de formación y práctica educativa en grupos de niños pequeños. Los datos demostraron que los profesionales entrevistados tienen formación en educación, y mayoría de los profesores licenciados, expertos en educación especial, forma generalista o por área de discapacidad, trastorno, maestros tengan una formación que se centra principalmente en la pedagogía de regentes. Además, los encuestados revelaron que las horas de trabajo imposible la formación continua; Otro punto a destacar fue que maestros regentes reportaron dificultad en enseñar a los niños con discapacidad, por no tener una formación adecuada.

PALAVRAS CLAVE: Formación de Maestros. Educación Infantil. La educación especial. deficiencia

ABSTRACT: With the prospect that the processes of formation of teachers are social and historical constitutions, whose theme is current research focus effect in recent decades, this article seeks to identify and discuss the profile of teachers working in early childhood education in classes of children with or without disabilities. Participated in this study twenty-six teachers (specialists and regents) operating in a city in the State of São Paulo. For the production of data, participants responded to an interview, the results obtained show signs to ponder on the initial training and continuing teachers, the experience of the professionals interviewed and the impact of these factors on the process of teacher training for and on educational practice in groups of small children. The data demonstrated that the professionals interviewed have a background in education, and most teachers have graduate degrees, experts in special education, generalist form and/or by area of disability/disorder, teachers have training that is primarily focused on Regents pedagogy. In addition, respondents revealed that the work impossible hours continuing training; Another point to be highlighted was that teachers Regents reported difficulty in teaching children with disabilities, for not having proper training.

KEYWORDS: Teacher Training. Child education. Special education. Deficiency

\section{Introdução}

A temática sobre a formação de professores para as crianças com e sem deficiência (BARROCO, 2008) deve ser pensada e debatida, pois “[...] são poucos os 
estudos que tomam por objeto o profissional que trabalha com a criança pequena, seus saberes e sua formação.” (MICARELLO, 2011, p. 213). Nessa perspectiva, este artigo destaca questões relacionadas à formação dos professores que atuam com as especificidades das crianças com deficiência, tais como: Será que estes profissionais estão preparados para trabalhar com a diversidade em sala de turmas de crianças pequenas? Os cursos de formação inicial e continuada estão dando conta de suprir as necessidades dos professores da Educação Infantil?

Para responder a esses questionamentos, tecemos reflexões acerca da temática, considerando que a Educação Infantil é um momento da vida da criança propício para aprendizagens essenciais ao desenvolvimento de capacidades especificamente humanas, que serão aperfeiçoadas em outras etapas educacionais. E, para isso, colocamos em evidência a pesquisa de mestrado finalizada de Amorim (2015), que abordou a formação dos professores para atuarem na Educação Infantil (EI) junto a crianças com e sem deficiência, assim como o currículo nessa etapa escolar.

Neste sentido, a Resolução $n^{\circ} .5$ (BRASIL, 2009c), em forma de lei, com força mandatória, destaca a criança como um sujeito histórico e de direitos, e a EI, como processo complementar à educação da família, com perspectivas de rompimento de relações de dominação e de promoção de acessibilidade de espaços, tempos, materiais, brinquedos e situações pedagógicas provocadoras da atividade de crianças com deficiência.

Em relação aos direitos infantis, as crianças com deficiências, público-alvo da Educação Especial (PAEE) ${ }^{4}$, devem estar inseridas em turmas comuns, sendo disponibilizado o serviço de Atendimento Educacional Especializado (AEE), cujo objetivo é eliminar as barreiras de aprendizagem e arquitetônicas que possam existir no meio em que estão inseridas, além de oferecer um conjunto de propostas educativas, recursos de acessibilidade e pedagógicos para complementar e/ou suplementar o ensino regular (BRASIL, 2008).

No que tange ao currículo na EI, as Diretrizes Curriculares Nacionais para a Educação Infantil (DCNEIs) (BRASIL, 2010), afirmam que se trata de escolhas articuladoras das experiências das crianças com os conhecimentos elaborados ao longo da história, sejam do patrimônio cultural, artístico, ambiental, social ou científico. Essa perspectiva de conceber o currículo objetiva promover o desenvolvimento integral da

\footnotetext{
${ }^{4}$ Incluem pessoas com deficiência, com transtornos globais do desenvolvimento e com altas habilidades ou superdotação (BRASIL, 2011).
} 
criança, de maneira a desenvolver propostas pedagógicas que contemplem, dentre outras possibilidades, interações, brincadeiras, imaginação, aprendizado, observação, experimentação. Conforme destaca Saviani (2003, p. 13) “[...] o trabalho educativo é o ato de produzir, direta e intencionalmente, em cada indivíduo singular, a humanidade que é produzida histórica e coletivamente pelo conjunto dos homens".

Com essa complexa e desafiadora tarefa, ao se apropriar de conhecimentos teórico-metodológicos que o instrumentalize, o professor “[...] [tem condições de] desenvolver métodos que conduzam ao desenvolvimento das potencialidades mentais, [para isso] ele precisa estabelecer uma programação de ensino, uma sistematização de conhecimentos que sirva de base para a formação de um verdadeiro desenvolvimento mental" (FACCI, 2004, p. 237). Esse trabalho demanda, pois, intencionalidade dirigida à transmissão de conhecimentos a partir do acesso à cultura historicamente produzida, bem como de uma atividade interventora e mediadora que busque atingir a zona de desenvolvimento próximo das crianças de maneira que elas possam, ativamente, se apropriar de bens culturais promotores de um máximo desenvolvimento de capacidades psíquicas tipicamente humanas.

Com base nessas ideias iniciais, este texto é composto como possibilidade de objetivação de resultados de pesquisa reveladora de nossas preocupações como professoras que, no exercício do trabalho docente e nas atividades de investigação, buscam identificar o perfil de professores que atuam com crianças pequenas, especialmente nesta ocasião, discutindo aspectos desse profissional atuante em turmas de crianças com e sem deficiência (BARROCO, 2008) na Educação Infantil, em um município do interior paulista.

\section{Percurso do caminho metodológico}

Conforme já mencionado, nesta exposição destacamos parte dos resultados obtidos em dissertação de mestrado de Amorim (2015), cujo propósito foi investigar uma realidade específica de atuação de professores tendo em vista as características do Atendimento Educacional Especializado (AEE) na EI em um município do interior paulista, expressado na itinerância desses profissionais em turmas de crianças pequenas, a partir de convênios com instituições que realizam o atendimento no contraturno. 
Trata-se de uma cidade populosa (aproximadamente 350.000 habitantes), com 61 escolas municipais de EI e 28 creches conveniadas.

A amostra reuniu um total de 26 participantes, assim distribuídos:

1. Professores do AEE na Educação Infantil: 17 participantes.

2. Professores de turmas regulares com crianças atendidas pelo AEE: 9 participantes.

Para a produção de dados foi elaborado e utilizado um roteiro de entrevista semiestruturada (MANZINI, 2003), que teve a revisão de dois juízes externos especialistas na área. As entrevistas aconteceram individualmente com os participantes, durante o período de julho a dezembro de 2013, e o registro dos dados ocorreu por meio de gravação em áudio.

De modo geral, nesse roteiro, foram abordadas questões sobre a graduação e especificidades da formação (cursos de especialização, lato sensu, stricto sensu, habilitação), participação em cursos e palestras na área de Educação Especial, carga horária e tempo de trabalho na EI, bem como questões relacionadas a outras atribuições de trabalho que estariam ligadas a esta etapa escolar e ao AEE.

\section{Resultados e discussões}

Com base nos dados oriundos da entrevista realizada com Professores Itinerantes (PI) - que realizam o AEE -, e com os Professores Regentes (PR) de turmas comuns, elegemos aspectos para discutirmos questões relativas à formação de professores que atuam com as crianças com deficiência, conforme revelam as proposições sequenciais.

\section{Professores Itinerantes (AEE)}

$\mathrm{O}$ perfil profissional dos professores itinerantes pode ser identificado com o quadro 1.

\begin{tabular}{|c|c|c|c|c|c|}
\hline \multicolumn{1}{|c|}{ Quadro 1 - Perfil Profissional dos Professores Itinerantes } \\
Participante & $\begin{array}{c}\text { Sexo } \\
\text { (F/M) }\end{array}$ & $\begin{array}{c}\text { Formação } \\
\text { Inicial }\end{array}$ & Pós-graduação & $\begin{array}{c}\text { Tempo de } \\
\text { trabalho - } \\
\text { Ed. } \\
\text { Infantil }\end{array}$ & $\begin{array}{c}\text { Tempo de } \\
\text { trabalho - } \\
\text { AEE (Ed. } \\
\text { Infantil) }\end{array}$ \\
\hline PI 1 & F & $\begin{array}{c}\text { Magistério } \\
\text { Pedagogia }\end{array}$ & Especialização AEE & 3 anos & 2 anos
\end{tabular}




\begin{tabular}{|c|c|c|c|c|c|}
\hline PI 2 & $\mathrm{~F}$ & Pedagogia & $\begin{array}{c}\text { Habilitação Deficiência Auditiva } \\
\text { Habilitação Deficiência Intelectual } \\
\text { Especialização Docência no Ensino Superior } \\
\text { Especialização Educação Inclusiva }\end{array}$ & - & 3 anos \\
\hline PI 3 & $\mathrm{~F}$ & $\begin{array}{l}\text { Magistério } \\
\text { Pedagogia } \\
\text { Letras }\end{array}$ & $\begin{array}{c}\text { Especialização em Literatura } \\
\text { Especialização em Supervisão } \\
\text { Especialização em Deficiência Intelectual }\end{array}$ & - & 3 anos \\
\hline PI 4 & $\mathrm{~F}$ & Pedagogia & $\begin{array}{l}\text { Habilitação Deficiência Auditiva } \\
\text { Habilitação Deficiência Intelectual } \\
\text { Especialização em Gestão } \\
\text { Lato sensu em Psicopedagogia }\end{array}$ & - & 3 anos \\
\hline PI 5 & $\mathrm{~F}$ & Pedagogia & $\begin{array}{l}\text { Especialização em Educação Especial } \\
\text { Habilitação em Deficiência Auditiva } \\
\text { Habilitação em Deficiência Intelectual } \\
\text { Especialização em Gestão } \\
\text { Especialização em Educação Especial e } \\
\text { Inclusiva } \\
\text { Especialização em Neuropsicopedagogia }\end{array}$ & - & 3 anos \\
\hline PI 6 & $\mathrm{~F}$ & $\begin{array}{c}\text { Serviço } \\
\text { social } \\
\text { Magistério } \\
\text { Pedagogia }\end{array}$ & $\begin{array}{c}\text { Habilitação em Deficiência Visual } \\
\text { Especialização em Educação Especial } \\
\text { Psicopedagogia Clínica e Institucional }\end{array}$ & 2 anos & 6 anos \\
\hline PI 7 & $\mathrm{~F}$ & Pedagogia & $\begin{array}{l}\text { Habilitação em Deficiência Intelectual } \\
\text { Habilitação em Deficiência Auditiva } \\
\text { Especialização Deficiência Intelectual } \\
\text { Lato sensu em Psicopedagogia }\end{array}$ & - & 5 anos \\
\hline PI 8 & $\mathrm{~F}$ & $\begin{array}{l}\text { Magistério } \\
\text { Pedagogia }\end{array}$ & $\begin{array}{c}\text { Lato sensu em Psicopedagogia } \\
\text { Especialização em Educação Especial }\end{array}$ & - & 4 anos \\
\hline PI 9 & $\mathrm{~F}$ & Pedagogia & $\begin{array}{l}\text { Habilitação em Deficiência Auditiva } \\
\text { Lato sensu em Psicopedagogia } \\
\text { Especialização em Educação Inclusiva }\end{array}$ & - & 4 anos \\
\hline PI 10 & $\mathrm{~F}$ & Pedagogia & $\begin{array}{l}\text { Especialização em Educação Infantil } \\
\text { Especialização em Educação Especial }\end{array}$ & - & 2 anos \\
\hline PI 11 & $\mathrm{~F}$ & Pedagogia & Especialização em Educação Especial & - & 2 anos \\
\hline PI 12 & $\mathrm{~F}$ & Pedagogia & $\begin{array}{l}\text { Especialização em Gestão Escolar } \\
\text { Especialização em Educação Especial } \\
\text { Especialização AEE }\end{array}$ & 1 ano & 4 anos \\
\hline PI 13 & $\mathrm{~F}$ & Pedagogia & $\begin{array}{c}\text { Especialização em Educação Especial } \\
\text { Especialização em Educação Inclusiva } \\
\text { Psicopedagogia Clínica e Institucional } \\
\text { Especialização em Neuropsicopedagogia }\end{array}$ & 1 ano & 4 anos \\
\hline PI 14 & $\mathrm{~F}$ & Pedagogia & Especialização em Psicopedagogia & 2 anos & 3 anos \\
\hline PI 15 & M & Pedagogia & $\begin{array}{l}\text { Especialização em Educação Especial } \\
\text { Especialização em Gestão Escolar } \\
\text { Lato sensu em Psicopedagogia } \\
\text { Especialização em Autismo } \\
\text { Neuropsicopedagogia Inclusiva e Clínica }\end{array}$ & 2 anos & 5 anos \\
\hline PI 16 & $\mathrm{~F}$ & $\begin{array}{l}\text { Magistério } \\
\text { Pedagogia }\end{array}$ & $\begin{array}{c}\text { Especialização em Educação Especial } \\
\text { Habilitação Deficiência Intelectual } \\
\text { Habilitação Deficiência Auditiva }\end{array}$ & - & 3 anos \\
\hline PI 17 & $\mathrm{~F}$ & Pedagogia & $\begin{array}{c}\text { Especialização em Educação Especial } \\
\text { Especialização AEE } \\
\text { Lato sensu em Psicopedagogia }\end{array}$ & - & 3 anos \\
\hline
\end{tabular}


Fonte: Adaptado de AMORIM, G. C. Organização e Funcionamento do Atendimento Educacional Especializado na Educação Infantil: estudo de caso, 2015, p. 58.

Diante dos dados do quadro 1, alguns pontos merecem atenção, especialmente aqueles concernentes ao perfil dos professores itinerantes: desses profissionais, há predominância do sexo feminino, 16:1. De acordo com o estudo exploratório sobre o professor brasileiro realizado pelo Ministério da Educação (BRASIL, 2009a), há prevalência do sexo feminino principalmente de profissionais atuantes em Escolas de Educação Infantil, seja com crianças de até três anos ou com aquelas um pouco maiores , de quatro a cinco anos, o que pode ser reafirmado no estudo ora apresentado e discutido.

Em relação à formação, $100 \%$ dos profissionais entrevistados possuem formação em Pedagogia. Em estudo realizado por Tartuci e Flores (2013), o perfil de formação inicial dos professores atuantes no AEE é predominantemente em Pedagogia, o que é ratificado também nos dados produzidos na investigação focada neste artigo (AMORIM, 2015). Do total dos entrevistados, $41 \%$ tiveram formação em Educação Especial de forma generalista, 53\% tiveram formação generalista e em outras áreas de deficiência/transtorno (auditiva, intelectual, visual e autismo) e 6\% somente em psicopedagogia.

Conforme art. 12, da Resolução CNE/CEB nº. 4/2009 (BRASIL, 2009b), o professor atuante no AEE deve ser habilitado para a docência, o que requer formação específica na Educação Especial. Em relação à investigação de Amorim (2015), dezesseis participantes estão em conformidade com a resolução, pois possuem a graduação em Pedagogia e formação complementar na área da Educação Especial, e um possui somente psicopedagogia. Contudo, a formação em Educação Infantil foi referida por apenas $6 \%$ dos professores.

Gatti (2010) relata, a partir de pesquisa, que disciplinas referentes à Educação Infantil e Educação Especial são pouco apresentadas nos currículos das licenciaturas do curso de Pedagogia. Essa estudiosa assevera que a abordagem desses cursos de licenciatura é genérica, sem referenciar ou articular intencional e diretamente possíveis práticas educativas com base em fundamentos teóricos capazes de instrumentalizar o trabalho do profissional em formação. A autora reforça ainda a insuficiência da formação inicial no sentido de se basear em um conjunto disciplinar disperso e fragmentado, com abordagens didático-pedagógicas meramente descritivas, com poucos cursos que permitam um aprofundamento em relação à Educação Infantil. 
Assinalar que o professor não possui cursos em seus processos de formação inicial e continuada não procede, a partir dos dados oriundos da pesquisa realizada por Amorim (2015), com dados comprobatórios acerca da quantidade de cursos realizados pelos participantes entrevistados nesse estudo: seis participantes possuem três cursos de formação complementar, quatro participantes possuem quatro cursos e um participante possui seis cursos. A questão que nos desafia a pensar é a aparente fragilidade curricular desses cursos para uma atuação pedagógica humanizadora desses profissionais. Isto é, esses cursos preparam qualitativamente para o exercício docente, já que os sujeitos entrevistados relatam dificuldades e falta de elementos instrumentalizadores para o êxito de sua atuação pedagógica?

Precisamos de uma formação problematizadora, que nos coloque a par dos desafios a serem enfrentados em sala de aula, que nos faça refletir sobre a heterogeneidade presente dentro das escolas de educação básica, sobre as necessidades que os alunos levam para esse contexto e as contribuições que os conteúdos trabalhados pela área do conhecimento exercem na constituição histórica e cultural desses alunos e, ainda, na necessidade que temos de flexibilizar e construir "pontes" para que esses conhecimentos sejam apropriados por alunos com ou sem necessidades educacionais especiais. (VIEIRA, 2008, p. 224).

Concordamos com Paulino (2014, p. 8) acerca de que o trabalho docente especificamente na Educação Infantil apresenta “[...] a fragilidade da função docente, no que tange à formação mínima exigida em lei para atuar na EI quanto na formação continuada", o que está em consonância com os dados e questionamentos da investigação apresentada, especialmente no que se refere à qualidade dos cursos de formação inicial e continuada para o êxito e a plenitude dos processos de ensino e de aprendizagem na infância.

Para ampliação dessas proposições, Michels (2006, p. 421) salienta que “[...] o professor assume papel de gestor da educação e a sua formação deve reafirmar tal função". A pesquisa de Amorim (2015) aponta para esse movimento dos professores que estão se qualificando na área que atuam, realizando formação complementar, em busca de aprimoramento do papel docente em turmas de crianças pequenas.

PI 11: [...] esse ano não me sobrou tempo e fisicamente não tem como, trabalho o dia inteiro, tenho 3 dias ATP, então, fica complicado. No fundamental trabalho todos os dias, 20 horas semanais, isso só no fundamental, mais 20horas semanais na Educação Infantil e depois ainda tem o ATP de segunda das 17 h15 até 20 h15 e de terça e quinta das $17 \mathrm{~h} 15$ até $19 \mathrm{~h}$ e ainda tenho a minha casa para cuidar. 
Esta narrativa de PI revela aspectos de dificuldades para a realização de estudos em nível de formação continuada, devido a uma carga horária que inviabiliza a participação em cursos de curta e longa duração, em congressos ou destinação de tempo para o estudo. Os dados demonstram que $76 \%(\mathrm{n}=13)$ possuem carga horária de 20 horas, $18 \%(n=3)$ de 25 horas e $6 \%(n=1)$ de 28 horas, sendo que, 53\% (n=9) dos PI exercem outra função e $47 \%(n=8)$ não exercem outra função além da itinerância. Isso “[...] sem contar que o acesso a cursos de formação continuada é dificultado por uma série de razões, tais como necessidade de investimento financeiro, indisponibilidade de tempo determinada por excessiva carga horária de trabalho", conforme destacado por Miranda (2013, p. 48). Destaca-se que PI é uma das três participantes que possui apenas um curso de formação complementar, cuja justificativa para a falta de cursos aparece atrelada à carga horária extra, conforme apontam os dados, assumida por esses profissionais.

Um dos fatores que levam os professores a realizarem jornadas duplas e até mesmo triplas são os salários baixos. Zibetti e Pereira (2010, p. 265) enfatizam que o cerne do trabalho envolve "[...] jornadas exaustivas, salários insuficientes e demandas que extrapolam o ambiente profissional”.

$\mathrm{Na}$ direção dessas ideias e dos desafios vividos numa sociedade capitalista como a nossa, Facci $(2004$, p. 14) afirma que "[...] os professores têm que trabalhar até três turnos para sobreviver e investir na sua própria formação", o que os prejudica e os distancia de uma prática educativa humanizadora e formadora das máximas possibilidades humanas nas crianças com as quais trabalha.

\section{Professores Regentes}

Os professores regentes da sala comum possuem formação inicial, predominantemente em Pedagogia, e formação complementar em Psicopedagogia. A média de tempo de trabalho na EI da rede municipal é de 12 anos.

\begin{tabular}{|c|c|c|c|}
\hline \multicolumn{1}{|c}{ Quadro 2 - Perfil profissional dos Professores Regentes } \\
\hline Participante & Formação Inicial & Pós-graduação & $\begin{array}{c}\text { Tempo de } \\
\text { trabalho - Rede } \\
\text { Municipal - } \\
\text { Educação } \\
\text { Infantil }\end{array}$ \\
\hline PR 1 & $\begin{array}{c}\text { Pedagogia } \\
\text { Serviço social }\end{array}$ & Lato sensu em Psicopedagogia & 7 anos
\end{tabular}




\begin{tabular}{|c|c|c|c|}
\hline PR 2 & Pedagogia & Especialização em Psicopedagogia Institucional & 20 anos \\
\hline PR 3 & $\begin{array}{c}\text { Magistério } \\
\text { Desenho Industrial }\end{array}$ & $\begin{array}{c}\text { Especialização em Docência no Ensino Superior } \\
\text { Especialização em Educação Infantil }\end{array}$ & 20 anos \\
\hline PR 4 & $\begin{array}{l}\text { Magistério } \\
\text { Pedagogia }\end{array}$ & $\begin{array}{l}\text { Lato sensu em Psicopedagogia } \\
\text { Especialização em Educação Infantil }\end{array}$ & 6 anos \\
\hline PR 5 & Pedagogia & Lato sensu em Psicopedagogia & 3 anos \\
\hline PR 6 & $\begin{array}{l}\text { Psicologia } \\
\text { Pedagogia }\end{array}$ & Lato sensu em Psicopedagogia & 3 anos \\
\hline PR 7 & $\begin{array}{l}\text { Magistério } \\
\text { Pedagogia }\end{array}$ & $\begin{array}{l}\text { Lato sensu em Psicopedagogia } \\
\text { Especialização em Educação Especial }\end{array}$ & 22 anos \\
\hline PR 8 & Pedagogia & $\begin{array}{c}\text { Especialização em Docência no Ensino Superior } \\
\text { Mestrado Educação Especial (UFSCAR) } \\
\text { Doutoranda Educação Especial (UFSCAR) }\end{array}$ & 6 anos \\
\hline PR 9 & $\begin{array}{l}\text { Artes plásticas } \\
\text { Pedagogia }\end{array}$ & Especialização em Educação Infantil & 22 anos \\
\hline
\end{tabular}

Fonte: AMORIM, G. C. Organização e Funcionamento do Atendimento Educacional Especializado na Educação Infantil: estudo de caso, 2015. p. 64.

O perfil de formação dos professores da sala comum em nível de pós-graduação está prevalentemente voltado à psicopedagogia, como se pode observar, sendo que apenas um participante (PR 8) possui mestrado concluído e doutorado em andamento.

Destaca-se a formação de PR 3, que possui formação em Desenho Industrial e magistério, não tendo graduação em Pedagogia, com atuação na Educação há 20 anos. Destaca-se que esta foi a participante que menos esclareceu a sua atuação, afirmando que a sua formação não é específica e que necessita do professor do AEE para orientar e intervir em determinados momentos.

Em relação à formação voltada para as necessidades da inclusão, foi relatada a dificuldade na falta de preparo dos professores ao receberem suas crianças PAEE, por não saberem como lidar e ensinar os mesmos, a exemplo da fala de PR 2:

PR 2: A Educação (Secretaria Municipal) tem a formação continuada que é no começo do ano, tem em fevereiro e tem em agosto depois das férias, tem vários cursos, vem o folder e você escolhe, tem cursos voltados para inclusão para a área de deficiência [...], não é assim você tem criança especial e você foi selecionada para esse tipo de curso voltado para deficiência do seu aluno, não tem isso, você recebe o aluno e você se vira e corre atrás do prejuízo, é assim que funciona [...] (grifo nosso).

Tais proposições ajuízam-nos a refletir sobre a promoção e a realização de cursos de formação dirigidos à plenitude do exercício docente. Conforme propõe Michels (2006), a atuação do professor em turmas de crianças com e sem deficiências 
requer a tomada de consciência sobre as especificidades de seu trabalho como uma condição essencial para o exercício pedagógico exitoso e, portanto, humanizador de sua função. No entanto, conforme PR 2, embora haja a proposição de cursos com a perspectiva de instrumentalização teórica do professor, eles são escolhidos pelos participantes e não diretamente voltados àqueles profissionais atuantes com crianças com deficiência. Neste sentido, essa exposição é reveladora: “[...] você recebe o aluno e você se vira e corre atrás do prejuízo, é assim que funciona” (PR 2, grifos nossos).

Vale ressaltar que a legislação prevê que os cursos de formação de professores sejam capazes de capacitá-los para receber, atender e educar, nas turmas com as quais trabalham, em que há crianças com e sem deficiência (BARROCO, 2008).

Com a defesa acerca da instrumentalização teórica do professor para a tomada de consciência sobre suas escolhas didático-metodológicas, Facci (2004) assevera a emergência de apropriação de conhecimentos culturais produzidos pela humanidade ao longo de sua história:

É necessário pensar a formação do professor como um processo que promova a sua própria humanização para além do senso comum e que, na qualidade de membro atuante na sociedade, possa colaborar com a transformação social, a qual tem como pressuposto a transformação da sua própria consciência (FACCI, 2004, p. 250).

Na mesma linha de pensamento, Martins (2009) anuncia a necessidade de uma formação que dê a oportunidade de personalizar as estratégias educacionais de maneira individual, assim, considerando a experiência pessoal do profissional. A autora ainda reforça a ideia de sólida preparação teórica e metodológica dos professores, para que sejam capazes de dirigir, consciente e intencionalmente, situações reais, bem como resolver problemas vivenciados com base nos conhecimentos apropriados em cursos de formação inicial e de formação continuada. Neste sentido, a defesa é a de que:

Há que se fazer esta educação um processo de luta contra a alienação, sem desprezar que ela é alicerçada nas relações sociais de produção, na organização econômica e política da sociedade capitalista e não na subjetividade dos indivíduos [...] Assim sendo, este é um processo que ao mesmo tempo exige a transformação das circunstâncias e das consciências, apenas possível em educação quando o trabalhadorprofessor objetiva-se no produto de seu trabalho, tendo, neste produto, a promoção intencional da humanização do outro e da sua própria humanidade. (MARTINS, 2009, p. 148-149). 
Considerando essa luta contra a alienação, Facci (2004) frisa que é necessária uma discussão com o intuito de oferecer a expansão de oportunidades da educação e formação, como um meio de favorecer a superação gradual e efetiva das desigualdades e exclusão social. Esse processo educacional exige consciência de que há um antagonismo "entre as propostas pedagógicas hoje tão na moda, que objetivam a mera adaptação do indivíduo ao já existente, e as propostas pedagógicas que têm como princípio a formação do indivíduo como sujeito-transformador da sua realidade" (OLIVEIRA, 2006, p. 22-23).

Oliveira (2006) ainda assegura que é imprescindível a apropriação da herança cultural criada histórica e socialmente pelas gerações. Somente assim cada pessoa poderá objetivar-se como ser social, sendo capaz de transformar a sua realidade por meio de sua atividade. A autora destaca que para concretizar uma atividade, acontece um ato de consciência, que não significa necessariamente uma consciência dessas ações:

Ao objetivar-se cria sempre novas necessidades, novas técnicas e, de igual modo, novos conhecimentos científicos, filosóficos e artísticos. Cria, assim, a cultura. Esse processo contínuo e ininterrupto de apropriação-objetivação, portanto, é instigado pela necessidade social que gera cada vez mais novas necessidades, não previstas pela natureza, bem como as respostas mais adequadas a elas. (OLIVEIRA, 2006, p. 8).

Isso significa que a atividade expressa no trabalho educativo:

É exatamente aquela que está organizada de modo a que o educando possa desenvolver-se como sujeito transformador em seu contexto social, não só conhecendo a complexidade da prática social existente, mas também seus limites no sentido de contribuir com sua atuação para as transformações desse contexto e de si mesmo. (OLIVEIRA, 2006, p. 24).

Facci (2004, p. 227) declara que "[...] o trabalho educativo posiciona-se, em primeiro lugar, em relação a objetivações produzidas historicamente; e, em segundo lugar, sobre a humanização dos indivíduos". A prática educativa possui, então, uma função mediadora entre crianças e conhecimentos, superando assim, a alienação.

É necessário pensar a formação do professor como um processo que promova a sua própria humanização para além do senso comum e que, na qualidade de membro atuante na sociedade, possa colaborar com a transformação social, a qual tem como pressuposto a transformação da sua própria consciência. (FACCI, 2004, p. 250). 
Silva (2009) alerta que uma educação inclusiva, dirigida à formação plena da pessoa, constitui-se como um processo que envolve e possibilita sua participação ativa no cenário educacional e social mais amplo, superando a perspectiva de uma educação voltada à adaptação da criança, do jovem ou do adulto. Na direção dessas ideias, Correia (2008) destaca que, para uma educação efetivamente inclusiva, há a exigência de processos e programas de formação de professores que permitam a apropriação de conhecimentos capazes de instrumentalizá-los para a percepção - e para uma atuação pedagógica intencional - de possíveis dificuldades, problemáticas ou deficiências dos seus alunos. Com isso, a escola torna-se cenário que vai além do acesso aos portões, mas que ofereça uma educação de qualidade, considerando que, potencialmente, se trata de um ambiente dirigido à promoção da formação humana, em níveis qualitativos e sofisticados.

Concordamos com Jesus e Effgen (2012, p. 19), para quem a escola é um ambiente de formação docente, quando "abre caminhos para que o educador adicione a investigação aos seus saberes-fazeres". As autoras ainda trazem a questão da inclusão escolar como forma de fomentar o processo de formação docente, com a reflexão sobre a prática - processo que requer conhecimentos científicos promotores de uma leitura crítica sobre o que é vivenciado nas escolas, assim como podem subsidiar projetos capazes de transformações.

Meirieu (2002, p. 34) reconhece que, nas escolas, se faz necessário “[...] descobrir novos meios para que a educação seja um lugar de partilha e não de exclusão [...] [uma vez que] a pedagogia pode se constituir como uma tensão permanente entre o que escraviza e o que alforria" (MEIRIEU, 2002, p. 125). Nesse sentido, ao promover a inclusão, a escola pode se tornar espaço de criação de uma consciência crítica sobre o paradoxo da sociedade:

Faz-se necessária a experiência com os alunos que apresentam deficiência. Sendo assim, o professor se permitirá na escola conhecer as diferenças dos alunos ao compartilhar experiências nas salas de aula e, consequentemente, desenvolver a consciência crítica sobre as contradições das relações sociais também presentes no cotidiano escolar. Outro fator importante na inclusão de alunos com deficiência na escola pública é a oportunidade do convívio com colegas sem deficiência, fazendo com que se percebam indivíduos capazes de desenvolver suas dimensões social, psíquica, biológica e laboral. (COSTA, 2012, p.92). 
Para ampliação dessas considerações, em pesquisa recente, Paulino (2014) apresenta o perfil profissional de professores com tempo de atuação na Educação Infantil de oito a doze anos. De modo particular, na pesquisa em discussão (AMORIM, 2015), esse tempo variou de três a vinte e dois anos de atuação profissional em turmas de crianças de até cinco anos.

Pelo exposto com os dados socializados e discutidos, nos limites deste texto, aspectos sobre a formação inicial e continuada de professores atuantes na Educação Infantil foram abordados na perspectiva de refletirmos sobre como as propostas desses momentos podem caracterizar ou não avanços qualitativos em suas práticas pedagógicas, considerando, pois, o tempo de experiência docente e o quanto essas formações têm impactado suas práticas educativas.

\section{Considerações Finais}

Ao longo deste texto, empreendemos esforços para discutir aspectos da formação inicial e continuada dos professores que atuam com as crianças com e sem deficiência na Educação Infantil. No conjunto das reflexões, destacamos considerações referentes à formação docente, especialmente se aquela oferecida aos professores investigados torna-se capaz de instrumentalizar esses profissionais teórica e metodologicamente para que eles planejem, desenvolvam e avaliem situações de ensino e de aprendizagem numa perspectiva humanizadora.

Com o estudo apresentado e discutido neste artigo, foi possível identificar a formação inicial e em nível de pós-graduação dos entrevistados, evidenciando que os professores itinerantes (especialistas) possuem cursos em nível de especialização, habilitação e/ou lato sensu; além disso, esses profissionais exercem jornadas duplas e/ou triplas para complementar a renda, uma vez que, na itinerância, a maioria tem jornadas de 20 horas. Já os professores regentes não possuem diferentes cursos em nível de pós-graduação, porém relataram dificuldade em ensinar a criança com deficiência por falta de preparo, o que podemos concluir que seria a falta de formação. Vale lembrar que se trata de um perfil profissional com atuação média de 12 anos na Educação Infantil. Desta forma, cabe a indagação se os profissionais trazem para si a reflexão acerca do papel social que exercem, questionado-se a respeito da prática 
pedagógica em consonância ao desenvolvimento da criança, processo que exige a busca de estratégias, métodos, conhecimentos instrumentalizadores de sua atuação consciente.

Este exercício de análise e de sistematizações provoca-nos a pensar sobre novas pesquisas cujo objetivo seja refletir acerca da formação e da prática docente, com a intenção de gerar possibilidades de oferecimento e garantia de uma educação potencialmente humanizadora, que inclua a todos no processo de constituição plena do humano em cada pessoa, com e sem deficiências.

Nessa direção, a escola torna-se espaço e tempo de humanização, tanto de professores quanto de crianças, tratando-se, portanto, um ambiente de onde podem emergir os processos e práticas efetivas de inclusão na sociedade. Eis uma das tarefas sociais das Escolas de Educação Infantil e, sobretudo, dos cursos de formação inicial e continuada de professores desse nível da escolaridade.

\section{Referências}

AMORIM, G. C. Organização e funcionamento do atendimento educacional especializado na educação infantil: estudo de caso. 2015. 137 f. Dissertação (Mestrado em Educação) - Universidade Estadual Paulista, Faculdade de Filosofia e Ciências, Marília, 23 de fevereiro de 2015.

BARROCO, S. M. S.. L.S. Vigotski e os novos fundamentos para a educação de pessoas com e sem deficiência. In: FAUSTINO, R. C.; CHAVES, M.; BARROCO, S. M. S. (Orgs.). Intervenções pedagógicas na educação escolar indígena: contribuições da Teoria Histórico-Cultural. Maringá: EDUEM, 2008. p. 91-111.

BRASIL. Decreto $\mathbf{n}^{\circ}$. 6.571 de 17 de setembro de 2008. Dispõe sobre o atendimento educacional especializado. Presidência da República/Casa Civil/Subchefia para Assuntos Jurídicos. Brasília. 2008.

Estudo exploratório sobre o professor brasileiro. Com base nos resultados do Censo Escolar da Educação Básica 2007, Brasília, DF, maio de 2009a.

Resolução no 4 de 2 de outubro de 2009. Institui Diretrizes Operacionais para o Atendimento Educacional Especializado na Educação Básica, modalidade Educação Especial, 2009b.

Resolução no $\mathbf{n}^{\mathbf{0}}$ 05/2009. Fixa Diretrizes Curriculares Nacionais para a Educação Infantil. Brasília, DF, 17 de dezembro de 2009c.

- Ministério da Educação. Secretaria de Educação Básica. Diretrizes curriculares nacionais para a educação infantil /Secretaria de Educação Básica. Brasília: MEC, SEB, 2010. 
Decreto $\mathbf{n}^{\circ}$ 7.611, de 17 de novembro de 2011. Dispõe sobre a educação especial, o atendimento educacional especializado e dá outras providências. Casa Civil; Subchefia para Assuntos Jurídicos, Brasília, DF, nov., 2011a. Disponível em: <http://www.planalto.gov.br/ccivil_03/_Ato2011-2014/2011/Decreto/D7611.htm>.

Acesso em: 15 fev. 2013.

CORREIA, L. M. Inclusão e necessidades educativas especiais: um guia para educadores e professores. 2. ed. Porto: Porto Editora, 2008, 192 p.

COSTA, V. A. da. Formação de Professores e educação inclusiva frente às demandas humanas sociais para quê? In: MIRANDA, T. G.; FILHO, T. A. G. (Orgs.). O professor e a educação inclusiva: formação, práticas e lugares. Salvador: EDUFBA, 2012.

FACCI, M. G. D. Valorização ou esvaziamento do trabalho do professor?: um estudo crítico-comparativo da teoria do professor reflexivo, do construtivismo e da psicologia vigotskiana. 1. ed. Campinas, SP: Autores Associados, 2004, 302 p. (Coleção formação de professores).

GATTI, B. A. Formação de professores no Brasil - características e problemas. Educ. Soc., Campinas, v. 31, n.113, p. 1355-1379, out./dez. 2010. Disponível em <http://www.scielo.br/pdf/es/v31n113/16.pdf>. Acesso em: 10 out. 2014.

JESUS, D. M. de.; EFFGEN, A. P. S. Formação docente e práticas pedagógicas: conexões, possibilidades e tensões. In: MIRANDA, T. G.; FILHO, T. A. G. (Orgs.). O professor e a educação inclusiva: formação, práticas e lugares. Salvador: EDUFBA, 2012.

MANZINI, E. J. Considerações sobre a elaboração de roteiro para entrevista semiestrutura. In: MARQUEZINE, M. C.; ALMEIDA, M. A.; OMOTE, S. (orgs). Colóquios sobre pesquisa em Educação Especial. Londrina: Eduel, 2003.

MARTINS, L. M. A personalidade do professor e a atividade educativa. In: Escola de Vigotski: contribuições para a Pedagogia e a Educação / FACCI, M. G. D.;TULESKI, S. C.; BARROCO, S. M. S. (Orgs.). Maringá: Eduem, 2009. p. 135-150

MEIRIEU, P. A pedagogia entre o dizer e o fazer: a coragem de começar. Porto Alegre: Artmed, 2002.

MICARELLO, H. Formação de professores da Educação Infantil: puxando os fios da história. In: ROCHA, E. A. C.; KRAMER, A. (Orgs.). Educação Infantil: enfoques em dialógo. 3. ed. Campinas, SP: Papirus, 2011.

MICHELS, M. H. Gestão, formação docente e inclusão: eixos da reforma educacional brasileira que atribuem contornos a organização escolar. Revista Brasileira de Educação, v. 11, n. 33, p. 406-560, set./dez. 2006. Disponível em: <http://www.scielo.br/pdf/rbedu/v11n33/a03v1133.pdf>. Acesso em: 7 jun. 2014.

MIRANDA, M. J. C.; DALL'ACQUA, M. J. C; HEREDERO, E. S.; GIROTO, C. R. M; MARTINS, S. E. S. O. Inclusão, educação infantil e formação de professores / 
Maria de Jesus Cano Miranda ... [et al.]. - Marília: Oficina Universitária; São Paulo: Cultura Acadêmica, 2013.

OLIVEIRA, B. A. de. Fundamentos filosóficos marxistas da obra vigostkiana: a questão da categoria de atividade e algumas implicações para o trabalho educativo. In: MENDONÇA, S. G. L.; MILLER, S. (Orgs.) Vigostki e a escola atual: fundamentos teóricos e implicações pedagógicas. 1. ed. Araraquara, SP: Junqueira\&Marin, 2006.

PAULINO, V. B. R. Sentidos que emergem do/circulam no trabalho docente na educação infantil. 2014. 208 f. Dissertação de mestrado, Programa de Pós-graduação em Educação na Universidade Federal do Espirito Santo. 2014.

SAVIANI, D. Pedagogia histórico-critica: primeiras aproximações. Campinas: Autores Associados, 2003.

SILVA L. M. da. Educação inclusiva e a formação de professores. $2009.90 \mathrm{f}$. Monografia apresentada como pré-requisito para conclusão do Curso de Especialização LatuSensu à distância em Educação Profissional e Tecnológica Inclusiva, Estado do Mato Grosso - Campus Cuiabá - Octayde Jorge da Silva. Cuiabá, 25 de setembro de 2009.

TARTUCI, D.; FLORES, M. M. L. A organização das práticas pedagógicas e da gestão e o atendimento educacional das crianças com necessidades educacionais especiais na educação infantil. In: I SIMPÓSIO INTERNACIONAL DE ESTUDOS SOBRE A DEFICIÊNCIA - SEDPcD/Diversitas/USP Legal - São Paulo, junho/2013. Anais... São Paulo: SEDPCD/DIVERSITAS/USP, 2013.

VIEIRA, A. B. Práticas pedagógicas e formação continuada de professores no ensino da língua materna: contribuições para a inclusão escolar. 2008. $246 \mathrm{f}$. Dissertação (Mestrado em Educação) - Programa de Pós-Graduação em Educação, Universidade Federal do Espírito Santo, Vitória, 29 de agosto de 2008.

ZIBETTI, M. L. T.; PEREIRA, S. R. Mulheres e professoras: repercussões da dupla jornada nas condições de vida e no trabalho docente. Educar em Revista, Curitiba, Brasil, n. especial 2, p. 259-276, 2010.

\section{Como referenciar este artigo}

AMORIM, Gabriely Cabestré et al. Formação de Professores da Educação Infantil: reflexões sobre a necessária instrumentalização teórica do profissional atuante com criança com ou sem deficiência. Revista Ibero-Americana de Estudos em Educação, Araraquara, v.12, n.1, p. 387-403, 2017. Disponível em: <http://dx.doi.org/10.21723/riaee.v12.n1.7597>. E-ISSN: 1982-5587.

Data de submissão: ago/2016

Aprovação final: dez/2016 